\title{
PENGgunaAN LEVELS OF INQUiRY DALAM MENINGKATKAN KETERAMPILAN Proses SAINS SisWA
}

\author{
Ratih Indah Puji Hartini ${ }^{1)}$ \\ 1) SMA Negeri 1 Pagaden, Subang, Jawa Barat \\ E-mail: tiehra@gmail.com
}

\begin{abstract}
Abstrak. Penelitian ini bertujuan untuk mendapatkan gambaran tentang peningkatan keterampilan proses sains siswa sebagai impact penerapan model pembelajaran levels of inquiry yang menggunakan kombinasi praktikum nyata-maya. Penelitian ini dilatarbelakangi oleh pentingnya keterampilan proses sains siswa di dalam pembelajaran fisika. Model pembelajaran levels of inquiry yang menggunakan kombinasi praktikum nyata-maya dapat digunakan sebagai solusi dalam upaya peningkatan keterampilan proses sains siswa. Penelitian pre-experimental dengan one-group pretest-posttest design dilakukan di kelas X di salah satu SMA Negeri Kabupaten Subang. Hasil penelitian menunjukkan bahwa adanya peningkatan keterampilan proses sains siswa dengan kategori tinggi (N-Gain 0.73).
\end{abstract}

Kata Kunci: model pembelajaran levels of inquiry, keterampilan proses sains, praktikum nyata-maya

\section{Pendahuluan}

Ilmu Pengetahuan Alam (IPA) khususnya fisika berkaitan dengan cara mencari tahu tentang alam secara sistematis, sehingga fisika bukan hanya penguasaan kumpulan pengetahuan yang berupa fakta-fakta, konsep-konsep, atau prinsip-prinsip saja tetapi juga merupakan suatu proses penemuan [1]. Oleh karena itu, pembelajaran fisika di sekolah harus menekankan pada pemberian pengalaman langsung kepada siswa untuk mengembangkan kompetensi agar dapat menjelajahi dan memahami alam sekitar secara ilmiah.

Salah satu tujuan pembelajaran fisika yang tercantum dalam Badan Standar Nasional Pendidikan (2006) yaitu agar peserta didik mampu mengembangkan pengalaman melalui percobaan agar dapat merumuskan masalah, mengajukan dan menguji hipotesis, merancang dan merakit instrumen, mengumpulkan, mengolah dan menafsirkan data, serta mengkomunikasikan secara lisan dan tertulis [1]. Keterampilan-keterampilan yang tertera dalam tujuan pembelajaran fisika menurut BNSP tersebut merupakan sejumlah keterampilan yang terdapat pada keterampilan proses sains. Hal ini menunjukkan bahwa salah satu kemampuan yang harus dilatihkan dalam pembelajaran fisika adalah keterampilan proses sains (KPS). Sehingga, pembelajaran fisika di sekolah selain memfasilitasi pengembangan kemampuan kognitif siswa juga harus mengembangkan keterampilan proses sains siswa.

Akan tetapi, pada kenyataannya proses di lapangan belum sesuai dengan harapan. Berdasarkan hasil pengamatan di beberapa sekolah keterampilan proses sains siswa masih rendah [2][3]. Hal ini didukung oleh hasil studi pendahuluan yang dilakukan di salah satu SMA negeri di kabupaten Subang yang menunjukkan fakta bahwa rata-rata keterampilan proses sains siswa juga masih masih dalam kategori rendah, dari skala 100 rata-rata hasilketerampilan proses sains siswa hanya mencapai angka 58,5. Hal tersebut dikarenakanproses pembelajaran masih bersifat teacher centered, berorientasi pada tes/ujian, guru hanya menyampaikan fisika sebagai produk, dan siswa masih menghafal informasi faktual. Selain itu, kegiatan praktikum juga jarang dilakukan karena keterbatasan alat dan waktu, sehingga kemampuan proses sains siswa tidak tergali secara optimal. Oleh karena itu, perlu ada langkah solutif agar tercipta kegiatan pembelajaran yang efektif dalam meningkatkan keterampilan proses sains.

Untuk menciptakan hal tersebut, dalam pembelajaransiswa harus terlibat aktif dan ikut berperan serta dalam proses perolehan suatu pengetahuan. Sedangkan guru lebih berperan sebagai fasilitator untuk mencapai tujuan tersebut serta merangsang keingintahuan mereka dan memotivasi kemampuan mereka. Baru-baru ini ada model pembelajaran terbaru yang dikembangkan oleh Carl. J. Wenning yang dirasakan mampu melatihkan keterampilan proses sains siswa pada pembelajaran fisika yaitu model pembelajaran levels of inquiry. Model pembelajaran levels of inquiry merupakan serangkaian pembelajaran yang berupa spektrum inkuiri yang di dalamnya terdiri dari tahapan discovery learning, interactive demonstrations, inquiry lessons, inquiry labs (guided, bounded, dan free), real world applications dan hypothetical inquiry (pure dan applied)). Model pembelajaran 


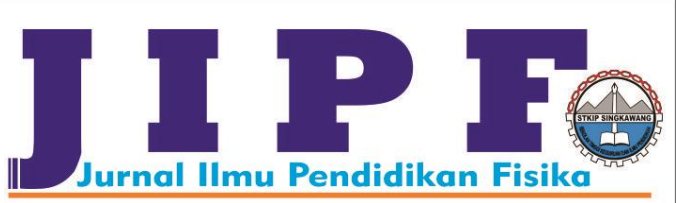

ini berbasis kepada dua hal yakni: (1) kecerdasan intelektual (intellectual sophistication), dan (2) pihak pengontrol (locus of control). Pihak pengontrol bergerak dari guru ke siswa secara berkesinambungan, dimulai dengan kegiatan discovery learning yang mana guru memegang penuh kontrol kegiatan pembelajaran, dan kontrol ini berangsur-angsur berkurang dan berpindah ke siswa hingga kegiatan hypothetical inquiry. Sedangkan untukkecerdasan intelektual, secara berkesinambungan meningkat dari discovery learning menuju hypothetical inquiry. Dengan tahapan-tahapan spektrum inkuiri, siswa akan mendapatkan pemahaman yang komprehensif dari seluruh kemampuan proses saintifik dan intelektual.

Namun, di dalam tahapan inquiry laboratory, yang dimanadi dalam tahap ini siswa melakukan penyelidikan terhadap suatu variable yang dimana kegiatan inquiry laboratory ini dilakukan secara nyata (real). Kegiatan praktikum secara nyata memang mempunyai peran yang sangat penting dalam pembelajaran sains terutama fisika [4]. Beberapa ahli menyatakan bahwa terdapat manfaat yang didapatkan dari pengunaan praktikum nyata, salah satunya adalah merupakan media yang potensial untuk memperkenalkan siswa terhadap konsep utama dan pengetahuan prosedur dan keterampilan dalam sains [4], terutama ketika mengenalkan prinsip-prinsip inkuiri [5]. Dalam konteks ini, siswa menggunakan metode-metode dan prosedur sains untuk menyelidiki suatu fenomena, memecahkan masalah dan menarik minat siswa untuk: (i) membangun pemahaman konsep, model dan teori sains; (ii) mendapatkan sebuah pemahaman cara dan metode dari scientific inquiry (kerja ilmiah), menanamkan kepedulian terhadap hubungan yang lebih komplek antara sains, teknologi, masyarakat dan lingkungan [4]. Keunggulan praktikum nyata adalahmampu membantu siswa untuk mengontrol pembelajarannya sendiri dalam mencari suatu pemahaman. Proses kegiatan praktikum harusmenyediakan kesempatan bagi siswa untuk bertanya, mengajukan hipotesis, dan mendesain suatu penyelidikan, atau dengan kata lain "minds on" harus beriringan dengan "hands on".

Akan tetapi, salah satu kelemahan dari kegiatan inquiry laboratory yang dilakukan secara nyataadalah siswa tidak mampu menjembatani siswa dalam memahami fenomena abstrak dan tidak semua materi fisika dapat dilakukan secara nyata dalam tahap ini. Solusi yang ditawarkan beberapa dekade terakhir ini adalah telah banyak hasil penelitian tentang penggunaan komputer yang dapat menciptakan suatu lingkungan dimana siswa terlibat ke dalam kegiatan kerja ilmiah [6].

Taasoobshirazi, dkk (2006) menyatakan bahwa pembelajaran inkuiri yang menggunakan komputer atau praktikum maya mempunyai dampak positif terhadap pemahaman konsep siswa [7]. Ada beberapa penelitian yang telah melakukan perbandingan ketercapaian siswa dalam laboratorium nyata dan maya dalam pembelajaran inkuiri yaitu: 1) Baser \& Durmus (2010): kedua kelompok baik yang menggunakan praktikum maya maupun praktikumnyatasecara signifikan berada pada level yang sama terhadap pemahaman konsep listrik dinamis [8]; dan 2) Zacharia \& Constantinou
(2011): baik kelas yang menggunakan praktikum nyata maupun praktikum maya sama-sama efektif dalam meningkatkan pemahaman konsep siswa dalam pokok bahasan suhu dan kalor.

Walaupun terdapat keuntungan-keuntungan dari penggunaan simulasi dalam praktikum mayauntuk meningkatkan inkuiri, terdapat juga beberapa isu dan kritikan terhadap penggunaan praktikum mayadalam pembelajaran inkuiri. Alasan penolakan penggunaannya menurut Clark (dalam Zacharia, 2007) adalah praktikum maya akan menghilangkan pengalaman siswa yang melibatkan manipulasi konkrit atau hands on dari penggunaan material secara fisik, dimana hal ini merupakan hal yang paling penting dari suatu pembelajaran [9]. Oleh karena itu, Zacharia \& Costantinou (2008) menyatakan bahwa secara khusus, penggunaan praktikum mayadianjurkan oleh sebagian para pendidik dilakukan jika hanya : (i) laboratorium nyatatidak tersedia, terlalu mahal atau terlalu susah didapatkan, (ii) praktikum yang dilakukan berbahaya, (iii) teknik praktikum terlalu rumit bagi siswa, atau (iv) memerlukan waktu yang sangat lama [10].

Berdasarkan adanya pendukung terhadap praktikum nyata dan praktikum maya, maka beberapa peneliti berusaha mengkombinasikan penggunaan praktikum nyata dan praktikum maya dan mencari cara yang terbaik dalam menggabungkan kedua metode praktikum tersebut. Tujuan utamanya adalah mencari manfaat dari potensi yang dimiliki oleh kedua metode praktikum tersebut untuk memaksimalkan efektivitas praktikum dalam kegiatan laboratorium [11]. Hasil beberapa penelitian (Zacharia, 2007; Oral, Bozkurt, \& Guzel, 2009 ; Farrokhnia, Reza, \& Esmailpoura, 2010; Olympiou \&Zacharia, 2010; Zacharia\&Olympiou, 2011;Saepuzaman, 2011; dan Gumilar, 2013) menunjukkan bahwa kombinasi dari praktikum nyata-maya lebih meningkatkan keterampilan proses sains siswa.

Kajian literature mengenai model pembelajaran levels of inquiry kaitannya dengan kombinasi metode praktikum nyatamaya belum ditemukan. Oleh karena itu, penelitian ini dilakukan untuk menyelidiki model pembelajaran sains levels of inquiryyang menggunakan kombinasi praktikum nyatamayauntuk keterampilan proses sains siswa. Dalam penerapannya tahapan levels of inquiry ada yang diterapkan secara parsial dan integrate. Pada penelitian ini penulis menerapkan levels of inquiry secara integrate dalam setiap pertemuan dengan tujuan agar kemampuan keterampilan proses sains dapat dilatihkan secara utuh melalui tahapan levels of inquiry dalam materi pokok pada setiap pertemuannya.

\section{METODE}

Metode penelitian yang digunakan adalah pre-experimental dengan desain penelitian one-grouppretest-posttest design. Populasinya merupakan seluruh siswa kelas X pada salah satu SMA Negeri di kabupatenSubang. Adapun yang menjadi sampel pada penelitian ini adalah siswa kelas X-1 dengan jumlah siswa sebanyak 37 orang yang dipilih secara randomized cluster sampling. 


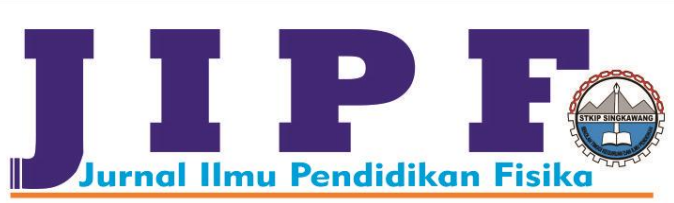

Untuk mengetahui peningkatan keterampilan proses sains yang dikembangkan melalui model pembelajaran levels of inquiry yang menggunakan kombinasi praktikum real-maya digunakanskor $n$-gain yang memiliki persamaan sebagai berikut:

$$
<g>=\frac{\%<G>}{\%<G>_{\max }}=\frac{\%<S_{f}>-\%<S_{i}>}{100-\%<S_{i}>}
$$

Adapun pengkategorian peningkatan kemampuan kognitif dan keterampilan proses sains siswa melalui rata-rata $\mathrm{N}$-gain, dapat dilihat pada Tabel 1.

TABEL 1

KRITERIA RATA-RATA N-GAIN

\begin{tabular}{cc}
\hline Koefisien Reliabilitas & Kategori \\
\hline$<\boldsymbol{g}>\geq 0,7$ & Tinggi \\
$0,3 \leq<\boldsymbol{g}><0,7$ & Sedang \\
$<\boldsymbol{g}><0,3$ & Rendah \\
\hline
\end{tabular}

\section{HASIL DAN PEMBAHASAN}

Peningkatan untuk keterampilan proses sains ditentukan oleh persentase rata-rata tes awal dan tes akhir, dan persentase rata-rata $\mathrm{N}$-gain. Pengolahan data persentase rata-rata tes awal, rata-rata tes akhir dan persentase rata-rata $\mathrm{N}$-gain selengkapnya dapat dilihat pada Lampiran D. Adapun perbandingan persentase rata-rata untuk tes awal dan akhir serta persentase rata-rata gain yang dinormalisasi $(\mathrm{N}$-Gain $)$ keterampilan proses sains ditunjukkan pada Gambar 1

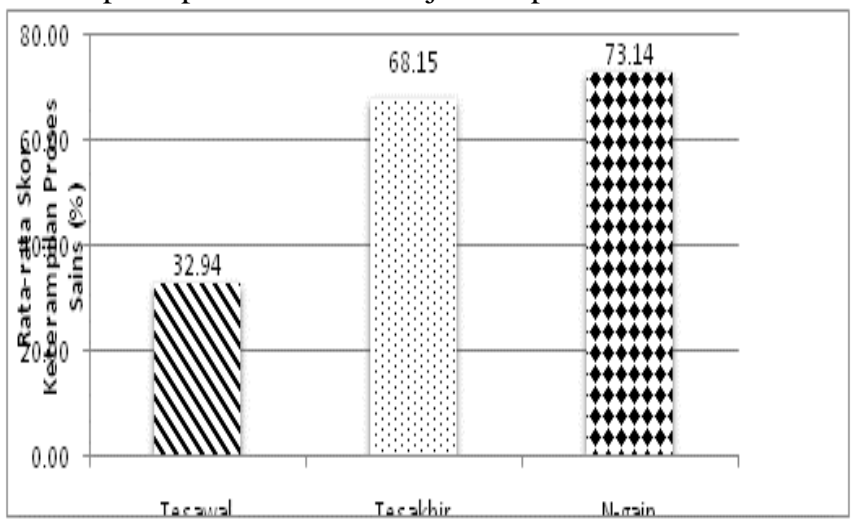

Gambar. 1 Perbandingan Persentase Rerata Skor Tes awal, Tes akhir, dan Persentase Rata-rata Gain yang Dinormalisasi (N-Gain).

Berdasarkan Gambar 1 dapat terlihat bahwa persentase rerata skor tes awalatau keterampilan proses sains awal siswa dikatakan kurang, hal ini dapat terlihat dari persentase rerata skor tes awal yang hanya mencapai 32,94\%.

Hasil tes akhir setelah pembelajaran memperihatkan kenaikan rerata nilai siswa. Persentase yang diperoleh adalah $65,15 \%$. Peningkatan keterampilan proses sains siswa sebelum dan setelah dilakukan pembelajaran sangat erat kaitannya dengan peroleh nilai gain yang dinormalisasi ( $N$-gain).

Berdasarkan gambar terlihat bahwa perolehan persentase nilai $N$-gainnya sebesar $73,14 \%$, dengan kategori tinggi.

Setelah dilakukan pembelajarandengan model pembelajaran levels of inquiry yang menggunakan kombinasi metode praktikum nyata-maya kemudian diberikan tes akhir untuk mengetahui pencapaian akhir keterampilan proses sains siswa dan mendapatkan nilai $N$-gainnya. Nilai $N$-gain menunjukkan bahwa kemampuan siswa secara keseluruhan meningkat dengan kategori tinggi.

Pada setiap tahapan inkuri pada model pembelajaran levels of inquiry telah melatihkan keterampilan proses sains secara berkesinambungan. Selain itu pada tahapan inquiry lab menghendaki penyertaan siswa dua kali untuk praktikum secara nyata dan praktikum secara maya, sehingga potensi dilatihkan keterampilan proses sains lebih sering lagi. Keunggulan dari model pembelajaran levels of inquiry dengan kombinasi praktikum nyata-maya, selain tahapan-tahapan pembelajarannya yang semakin tinggi tahapannya siswa mencari sendiri dan mendominasi pembelajaran, model ini juga mengajarkan siswa untuk berfikir dari tingkat yang konkret ke abstrak, sehingga lebih bermakna.

Pada praktikum nyata, siswa berlatih mengobservasi, berkomunikasi, merencanakan praktikum atau penguasaan konsep lainnya. Setelah mereka memiliki keterampilan proses yang cukup baik, mereka akan menerapkannya kembali untuk sistem yang lain dalam praktikum yang dilakukan secara maya Sehingga mereka lebih bisa mengeksplorasi dan melatih keterampilan proses sains mereka lebih luas dengan menggunakan praktikum maya.

Persentase rata-rata nilai tes awal, tes akhir dan $\mathrm{N}$-gain pada setiap aspek keterampilan proses sains dapat dilihat pada Gambar 2. Berdasarkan diagram batang pada Gambar 2, dapat dilihat bahwa persentase rata-rata $\mathrm{N}$-gain tertinggi terdapat pada aspek mengamati, sedangkan persentase rata-rata $\mathrm{N}$-gain terendah terdapat pada aspek merencanakan praktikum. Kategori peningkatan setiap aspek keterampilan proses sains berdasarkan nilai rata-rata $\mathrm{N}$-gain terhadap kriteria Hake, dapat dilihat pada Tabel 2.

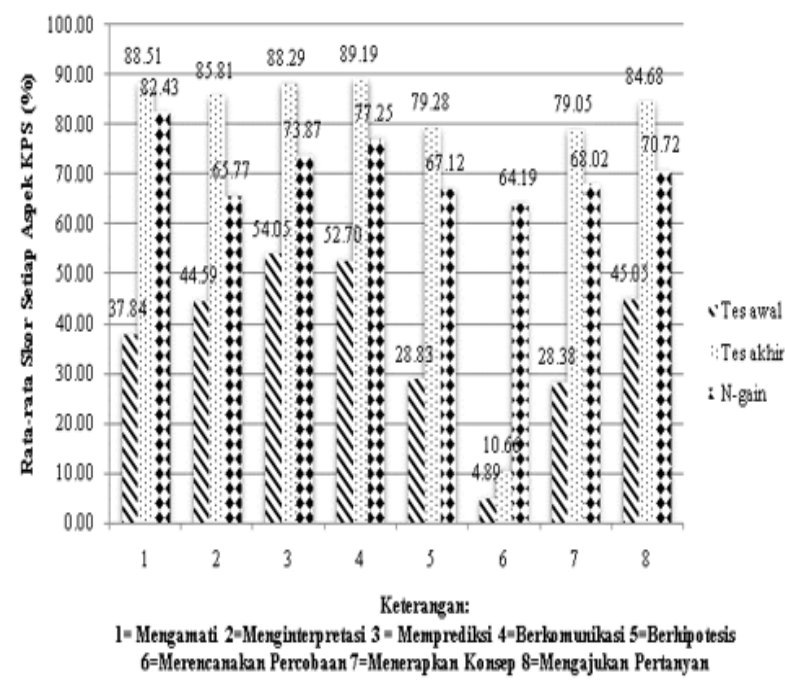

Gambar. 2 Perbandingan Rerata Skor Tes Awal, Tes Akhir, dan Persentase Rata-rata Gain yang Dinormalisasi (N-Gain) untuk Setiap Aspek KPS 


\section{JIP F。}

TABEL 1

KATEGORI PENINGKATAN N-GAIN UNTUK SETIAP ASPEK KETERAMPILAN PROSES SAINS

\begin{tabular}{llcl}
\hline No & \multicolumn{1}{c}{ Aspek KPS } & $\begin{array}{c}\text { Rata- } \\
\text { rata } \\
\text { N-gain }\end{array}$ & Kategori \\
\hline 1 & Mengamati & 0,82 & Tinggi \\
2 & Menginterpretasi data & 0,66 & Sedang \\
3 & Memprediksi & 0,74 & Tinggi \\
4 & Berkomunikasi & 0,77 & Tinggi \\
5 & Berhipotesis & 0,67 & Sedang \\
6 & Merencanakan praktikum & 0,64 & Sedang \\
7 & Menerapkan konsep & 0,68 & Sedang \\
8 & Mengajukan pertanyaan & 0,71 & Tinggi \\
\hline
\end{tabular}

Dari hasil analisis diketahuibahwa nilai persentase $N$-gain paling tinggi terdapat pada keterampilan mengobservasi sebesar 0,82 dengan kategori tinggi. Hal ini dapat terlihat dari matriks hubungan model pembelajaran levels of inquiry yang menggunakan kombinasi praktikum nyata-maya terhadap keterampilan proses sains pada Tabel 3, menunjukkan bahwa keterampilan mengobservasi hampir ada di setiap tahapan pembelajaran. Pada setiap tahap pembelajaran, siswa diberi kesempatan lebih luas untuk menggunakan indera sebanyakbanyaknya. Hal ini sesuai dengan pendapat Harlen (dalam Rustaman, dkk., 2005) bahwa siswa harus diberikan kesempatan untuk mengeksplorasi fenomena dan mencoba menggunakan keterampilan prosesnya [13].

Keterampilan merencanakan praktikum mendapatkan nilai $N$-gain paling rendah, karena pada model ini siswa harus merencanakan praktikumnya sendiri. Siswa belum terbiasa untuk menentukan variabel-variabel praktikum, alat dan bahan yang diperlukan, cara merangkai alat dan bahan, jenis data yang akan dikumpulkan, bentuk tabel untuk mengoleksi data hasil praktikum, dan menentukan langkah-langkah praktikum. Berbeda dengan pembelajaran sebelumnya yang sering menggunakan LKS yang bersifat cookbook, maka siswa mengalami kesulitan dalam merencanakan praktikum.

Secara keseluruhan, hasil penelitian ini tidak mengejutkan karena berdasarkan temuan sebelumnya (Zacharia, 2010; Saepuzaman 2011) menunjukkan bahwa pembelajaran yang menggunakan kombinasi praktikum nyata-mayadapat meningkatkan kemampuan keterampilan proses sains siswa. Dengan adanya kombinasi praktikum nyata-maya, siswa melakukan praktikum dua kali sehingga keterampilan proses sains dilatihkan dua kali [14][15].

Di sisi yang lain, teori belajar pengulangan menyatakan bahwa pengulangan dalam pembelajaran penting dilakukan. Walaupun beberapa ahli berpendapat bahwa pengulangan dalam pembelajaran merupakan kegiatan yang sedikit sekali kegiatan berpikirnya, tidak ada pengajaran untuk memahami tetapi menduplikasi, dan seringkali membosankan. Akan tetapi, hasilnya dapat terlihat bahwa dengan melakukan kembali proses praktikum secara maya dapat meningkatkan keterampilan proses sains siswa. Teori yang mendukung tentang pentingnya pengulangan dalam pembelajaran yakni : 1) teori psikologi Dava yang menyatakan bahwa dengan

adanya pengulangan maka daya-daya yang ada pada manusia akan berkembang; 2) teori psikologi Asosiasi atau Koneksionisme dengan tokoh yang terkenal Thorndike yang mengemukakan bahwa belajar ialah pembentukan hubungan antara stimulus dengan respons dan pengulangan terhadap pengalaman-pengalaman itu memperbesar peluang timbulnya respons benar; dan 3) Teori Psikologi Conditioning yang menyatakan bahwa perilaku individu dapat dikondisikan, dan belajar merupakan upaya untuk mengkondisikan suatu perilaku atau respons terhadap sesuatu [15]. Mengajar merupakan kegiatan yang membentuk kebiasaan, mengulangulang sesuatu perbuatan sehingga menjadi suatu kebiasaan dan pembiasaan tidak perlu selalu oleh stimulus yang sesungguhnya, tetapi dapat juga oleh stimulus penyerta.

Ketiga teori tersebut menekankan pentingnya prinsip pengulangan dalam belajar walaupun dengan tujuan yang berbeda. Walaupun kita tidak dapat menerima bahwa belajar adalah pengulangan seperti yang dikemukakan ketiga teori tersebut, karena tidak dapat dipakai untuk menerangkan semua bentuk belajar, namun prinsip pengulangan masih relevan sebagai dasar pembelajaran.

Pemberian pengalaman langsung dengan alat-alat yang nyata ternyata sangat penting sebelum diberikan konsepsi lain yang bersifat maya. Piaget menyatakan bahwa manusia cenderung berpikir dari hal yang sifatnya nyata menuju ke yang abstrak (concrete to abstract). Sesuai dengan hasil penelitian Zacharia \& Olympiou (2011) yang juga menyimpulkan bahwa urutan kombinasi praktikum memberikan dampak yang penting pada hasil belajar .

\section{KESIMPULAN}

Pada dasarnya penelitian ini dilakukan untuk mengetahui gambaran tentang peningkatan keterampilan proses sains siswa sebagai impact penerapan model pembelajaran levels of inquiry yang menggunakan kombinasi praktikum nyata-maya. Adapun temuan yang dihasilkan dari penelitian ini adalahketerampilan proses sains siswa pada materi rangkaian arus searah meningkat dengan kategori tinggi setelah mendapatkan pembelajaran dengan model pembelajaran levels of inquiry yang menggunakan kombinasi praktikum nyatamaya;menyajikan ringkasan dari uraian mengenai hasil dan pembahasan, mengacu pada tujuan penelitian. Berdasarkan kedua hal tersebut dikembangkan pokok-pokok pikiran baru yang merupakan esensi dari temuan penelitian.

Berdasarkan penelitian yang telah dilakukan, ada beberapa hal yang harus diperhatikan dalam penerapan model pembelajaran sains levels of inquiry yang menggunakan kombinasi praktikum nyata-maya pada materi rangkaian listrik arus searah, yakni pengaturan waktu untuk pengoptimalan kegiatan praktikum nyata-maya. Hal ini dikarenakan praktikum nyata akan memerlukan porsi waktu yang lebih lama dalam proses pelaksanaannya, sementara siswa akan melakukan kembali praktikum secara maya. Sebelum penelitian sebaiknya siswa dibiasakan untuk melakukan praktikum nyata dan diberikan pengarahan tentang penggunaan praktikum maya, agar tidak ada kendala teknis yang berarti pada saat penelitian. Sarana dan prasarana baik 


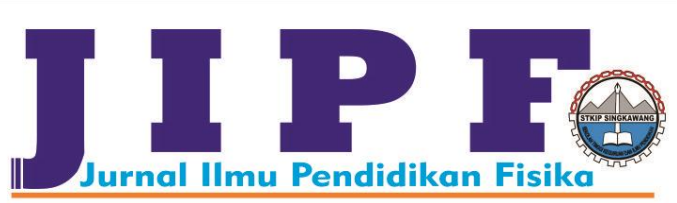

untuk kegiatan praktikum nyata dan praktikum maya harus tersedia dengan lengkap.

Berdasarkan hasil penelitian dan pembahasan yang telah dilakukan, peneliti merekomendasikan model pembelajaran levels of inquiry yang menggunakan kombinasi praktikum nyata-maya diterapkan pada konsep lain atau digunakan untuk mencari tahu bagaimana impactnya terhadap keterampilan berfikir tingkat tinggi yang laindisusun berdasarkan temuan penelitian yang telah dibahas. Saran dapat mengacu pada tindakan praktis, pengembangan teori baru, dan/atau penelitian lanjutan.

\section{UCAPAN TERIMAKASIH}

Ucapan terima kasih diberikan kepada STKIP Singkawang yang telah memfasilitasi penulis sehingga tulisan ini dapat dipublikasikan dalam berkala ilmiah STKIP Singkawang.

\section{DAFTAR PUSTAKA}

[1] BSNP, Panduan Penyusunan KTSP, Jakarta: Depdiknas, 2006.

[2] Setyawan, E.J., Penerapan Pembelajaran Inkuiri dengan Multiple Represensi untuk Meningkatkan Meningkatkan Kemampuan Kognitif dan Keterampilan Berfikir Kritis Siswa SMA, (Tesis), Sekolah Pascasarjana, Universitas Pendidikan Indonesia, Bandung, 2012.

[3] Rizal, R., Penerapan Pendekatan Demonstrasi Interaktif Dalam Pembelajaran Listrik Dinamis untuk Meningkatkan kemampuan Kognitif dan Keterampilan Proses Sains Siswa SMA, (Tesis), Sekolah Pascasarjana, Universitas Pendidikan Indonesia, Bandung, 2013.

[4] Hofstein \& Luneta, The Laboratory in Science Education: Foundations for The Twenty First Century, Science Education 88, hlm. 28-54, 2004.

[5] De Jong, T., Computer Simulations: Technological Advances in Inquiry Learning, Science, 312, hlm. 532533, 2006.

[6] Van Joolingen, W.R., de Jong, T., \& Dimitrakopoulou, A., Issues in computer supported inquiry learning in science, Journal of Computer Assisted Learning, 23 (2), hlm. 111-119, 2007.

[7] Taasoobshirazi, G., Zuiker, S. J., Anderson, K.T., \& Hickey, D.T., Enhancing Inquiry, Understanding, and Achievement in an Astronomy Multimedia Learning Environment. Journal of Science Education and Technology, 15(5), hlm.383-395, 2006.

[8] Başer, M. \& Durmuş, S., The Effectiveness Of Computer Supported Versus Real Laboratory Inquiry Learning Environments On The Understanding Of Direct Current Electricity Among Pre-Service Elementary School Teachers, Eurasia Journal of Mathematics, Science \& Technology Education, 6(1), hlm. 47-61, 2010.

[9] Zacharia, Z.C., Comparing and Combining Real and Virtual Experimentation: An Effort to Enhance Students' Conceptual Understanding of Electric Circiuits. Journal of Computer Assistes Learning, 23(2), hlm. 120-132, 2007.

[10] Zacharia, Z.C., \& Costantinou, C.P., Comparing the influence of physical and virtual manipulatives in the context of the Physics by Inquiry curriculum: The case of undergraduate students' conceptual understanding of heat and temperature .American Journal of Physics, 76 (4), hlm. 425-430, 2008.

[11] Zacharia, Z.C. \& Anderson, O. R., The effects of an interactive computer-based simulation prior to performing a laboratory inquiry-based experiment on students' conceptual understanding of physics, American Journal of Physics, 71(6), hlm. 618-629, 2003.

[12] Hake, R, R. (2002). Relationship of Individual Student Normalized Learning Gains in Mechanics with Gender, High-School Physics, and Pretest Scores on Mathematics and Spatial Visualization. [Online]. Tersedia: physics.indiana.edu/ hake/PERC2002hHake.pdf. (1 Oktober 2014).

[13] Rustaman, dkk., Strategi Belajar Mengajar Biologi. Malang: UM Press, 2005

[14] Olympiou, G., \& Zacharia, Z.C., Implementing a blended combination of physical and virtual laboratory manipulatives to enhance students' learning through experimentation in the domain of Light and Color, Journal of Education, Informatics and Cybernetics. 2 (1), 2010.

[15] Saepuzaman, D., Penerapan Model Pembelajaran Inkuiri dengan Kombinasi Eksperimen Nyata-Virtual Pada materi Rangkaian Listrik Arus Searah untuk meningkatkan Penguasaan Konsep dan Keterampilan Proses Sains Siswa, (Tesis), Sekolah Pascasarjanan Universitas Pendidikan Indonesia, Bandung, 2011.

[16] Zacharia, Z.C., \& Olympiou G., Physical Versus Virtual Manipulative Experimentation In Physics Learning. Journal Learning and Instruction, 21 (2011), hlm. 317 331, 2011

[17] De Porter, Bobbi dan Hernacki, Mike., Quantum Learning, Membiasakan Belajar Nyaman dan Menyenangkan, Terjemahan oleh Alwiyah Abdurrahman. Bandung: Penerbit Kaifa, 1992.

[18] Singgih Santoso, Mengolah data Statistik secara professional, Jakarta: PT Elex Media Komputindo Kelompok Gramedia, 2001.

[19] Farrokhniaa, Mohammad, R., \&Esmailpoura, A., "A Study on The Impact Of Real, Virtual And Comprehensive Experimenting On Students' Conceptual Understanding Of Dc Electric Circuits And Their Skills In Undergraduate Electricity Laboratory", Procedia Social and Behavioral Sciences, 2 (2010), hlm. 54745482, 2010.

[20] Gumilar, S., Penerapan Model Pembelajaran Inkuiri dengan Kombinasi Metode Eksperimen Nyata-Virtual Untuk Meningkatkatkan Pemahaman Konsep dan Keterampilan Berfikir Kritis Siswa, (Tesis), Sekolah Pascasarjanan Universitas Pendidikan Indonesia, Bandung, 2013.

[21] Oral, E, Bozkurt, \& Guzel., The Effect Of Combining Real Experimentation With Virtual Experimentation On Students' Success. Jurnal World Academy of Science, 
Engineering and Technology, 30 (256), hlm.1599-1604, 2009.

[22] Wenning, C. J., Levels of inquiry: Hierarchies of pedagogical practices and inquiry processes, Journal of Physics Teacher Education Online, 2(3), hlm. 3-11, 2012 